\title{
Review of Experimental Results Related to the Operation of Intermediate Band Solar Cells
}

\author{
Íñigo Ramiro, Antonio Martí,
}

\author{
Elisa Antolín, and Antonio Luque
}

\begin{abstract}
The intermediate band solar cell (IBSC) has drawn the attention of the scientific community as a means to achieve high-efficiency solar cells. Complete IBSC devices have been manufactured using quantum dots, highly mismatched alloys, or bulk materials with deep-level impurities. Characterization of these devices has led, among other experimental results, to the demonstration of the two operating principles of an IBSC: the production of the photocurrent from the absorption of two below bandgap energy photons and the preservation of the output voltage of the solar cell. This study offers a thorough compilation of the most relevant reported results for the variety of technologies investigated and provides the reader with an updated record of IBSC experimental achievements. A table condensing the reported experimental results is presented, which provides information at a glance about achievements, as well as pending results, for every studied technology.
\end{abstract}

Index Terms-Intermediate band solar cell (ISBC), new generation photovoltaics, solar cell characterization.

\section{INTRODUCTION}

$\mathbf{T}$ HE intermediate band solar cell (IBSC) was proposed as a means of enhancing the energy conversion of single-gap solar cells [1]. Different technological approaches have been investigated for the implementation of a high-efficiency IBSC. These can be divided into three large groups: nanostructures, such as quantum dots (QDs) [2]; highly mismatched alloys (HMAs); semiconductor alloys where band anticrossing effects take place [3]; and semiconductor bulk materials containing a high density of deep-level impurities (DLIs) [4]. Rising experimental efforts have been made in the last decade to advance in the investigation of this new concept (for a summary of current understanding of the IBSC operation, see [5]-[7]). Special care must be taken when analyzing and interpreting experimental results obtained by the conventional techniques used to characterize PV devices (a comprehensive guide to the understanding of the characterization of IBSCs can be found in [8]). In addition, resulting from the novelty of the IBSC operation, the development of specific experimental procedures [9], [10] is needed in order to characterize these devices.

A first distinction can be made among the variety of experimental evidences of IB-related phenomena: those obtained on complete IBSC - at device level - and those obtained on bare intermediate band (IB) materials-at material level. An IBSC can theoretically surpass the Shockley and Queisser limit for single-gap solar cells [11] by producing a higher current while maintaining a high-output voltage. The two key operating principles of an IBSC are the production of extra subbandgap photocurrent and the preservation of the output voltage and can therefore only be verified through characterization of IBSCs at device level and not at material level. However, when characterizing at the device level it is difficult to isolate the impact of a single IB-related phenomenon, because of the many other parameters that play a role in the operation of a solar cell. Hence, it is useful to perform the characterization at material level as a help to understand the device behavior.

Experimental evidence of IBSC behavior has been reported for different candidate materials in each of the three technological approaches listed before. So far, the two operating principles of an IBSC have only been demonstrated in QD-IBSCs, but in recent years, many promising results have been obtained for other technologies. The number of materials used in IBSC prototypes is increasing rapidly, which makes it hard to keep up with all the results. The purpose of this study is to gather, present and briefly describe, and discuss the most relevant results obtained in IBSC characterization in order to provide the reader with an updated record of IBSC experimental achievements.

This study is organized as follows. Section II reviews the basis of the IBSC operation and some phenomena that can be experimentally verified. Section III examines the most used experimental techniques for characterizing IBSCs or IB materials. Section IV presents a compilation of experimental results at device and material levels (only for those materials that have been used in complete IBSC prototypes). A table relating the IB-materials used in the fabrication of IBSCs and the experimental techniques used to verify IBSC behavior is presented in Section V. Section VI summarizes the conclusions of this study.

\section{FUndAMENTALS OF INTERMEdiATE BAND SOLAR Cell Operation}

An IB material is characterized by the existence of an IB, a band of allowed electronic states within the semiconductor fundamental bandgap $E_{G}$ separated by a true zero density of states from the valence band (VB) and the conduction band (CB). The IB gives rise to two additional subbandgaps $E_{H}$ and $E_{L}$, as depicted in Fig. 1. $E_{H}$ denotes the largest of both and $E_{L}$ 


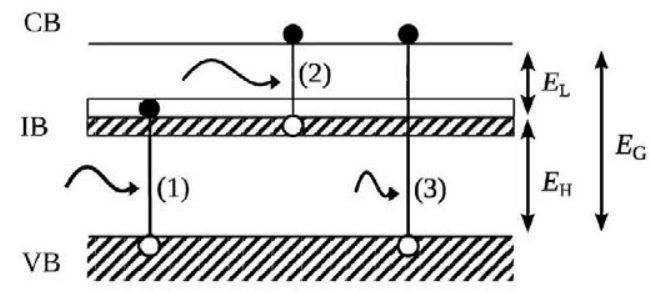

Fig. 1. Simplified band diagram of an IB material. The three bands (VB, $\mathrm{IB}$, and $\mathrm{CB}$ ), the three bandgaps $\left(E_{G}, E_{H}\right.$ and $\left.E_{L}\right)$, and the three possible interband transitions are indicated.
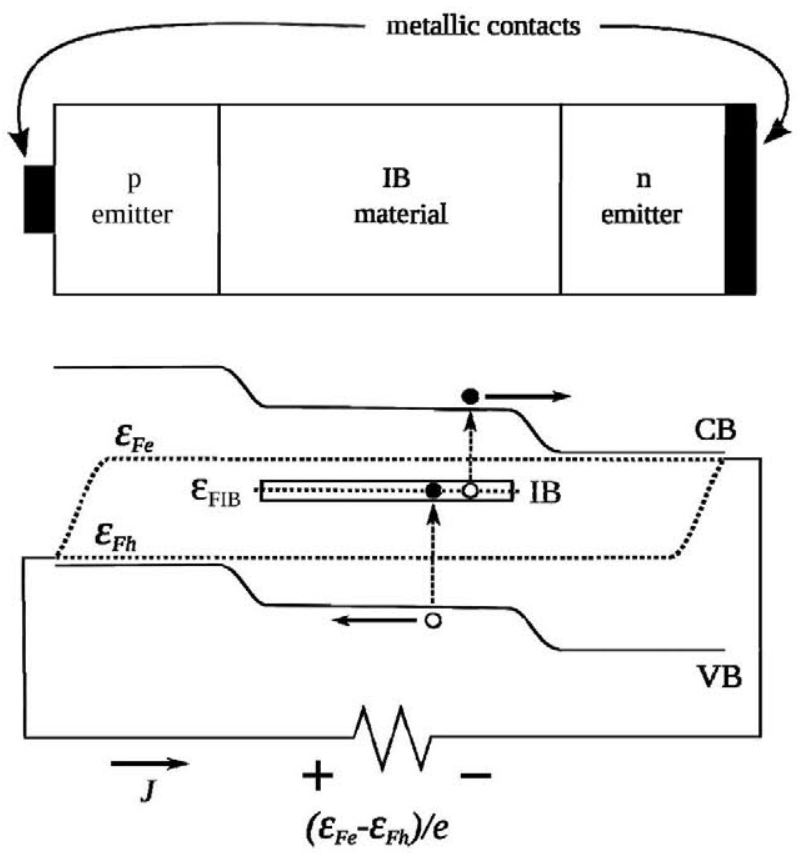

Fig. 2. (Top) Simplest conception of an IBSC and (bottom) simplified band diagram of an IBSC under operation. The production of TPPC is illustrated. The three quasi Fermi levels $\left(\varepsilon_{\mathrm{Fe}}, \varepsilon_{\mathrm{Fh}}\right.$ and $\left.\varepsilon_{\mathrm{FIB}}\right)$ are represented. The photogenerated current $J$ and the output voltage of the cell $\left(\varepsilon_{\mathrm{Fe}}-\varepsilon_{\mathrm{Fh}}\right) / e$ are indicated.

the narrowest, independent of which subbandgap is the upper or lower one. In the figure, the IB is placed closer to the $\mathrm{CB}$ than to the VB since it is the case for most of the IB-materials so far used in IBSCs. Photons from the solar spectrum with energy higher than these subbandgaps can potentially hand over their energy to electrons in the $\mathrm{VB}$ or to electrons in the IB, pumping them to the IB or the $\mathrm{CB}$, respectively, causing transitions labeled 1 and 2 in the figure. Transition 3, from the VB to the $\mathrm{CB}$, is possible through the absorption of supra-bandgap energy photons.

Experimental techniques applied to conventional semiconductors for characterizing their bandgap $E_{G}$ can also be used to characterize $E_{H}$ and $E_{L}$. Optical absorption measurements, for example, should reveal features related to these new gaps. And, as a counterpart to this absorption, the luminescent spectra of an IB-material should also reveal $E_{G}, E_{H}$, and $E_{L}$ when properly excited [12].

The simplest conception of an IBSC is sketched in Fig. 2 (top). An IB material is sandwiched between two semiconductor emitters: one p-doped and one n-doped. Metallic ohmic contacts are placed at each of the emitters. As in a conventional solar cell, the p- and n-emitters act as selective contacts for holes and electrons, respectively, which allow the collection through the metallic contacts of part of the photogenerated carriers. Electrons pumped from the VB to the $\mathrm{CB}$ in a two-step process via the absorption of two subbandgap photons will also be collected and contribute to the photocurrent of the solar cell, labeled $J$ in Fig. 2 (bottom). Hence, the production of photocurrent should take place in an IBSC when illuminated with two-color subbandgap photons: one of them with energy higher than $E_{L}$ but lower than $E_{H}$ and the other with energy higher than $E_{H}$ but lower than $E_{G}$. This is commonly known as two-photon subbandgap photocurrent and is the first key operating principle of an IBSC.

Throughout this study, for a given IBSC, the term reference cell will refer to a solar cell that consists of the same semiconductor structure as the corresponding IBSC but in which the IB material has been replaced by a conventional (single gap) semiconductor. If the collection of the two-photon photocurrent is efficient, the IBSC should present a short-circuit current $J_{\mathrm{SC}}$ larger than that of its reference cell.

In order for the two-photon photocurrent to achieve the highest possible value, partial filling of the IB is necessary so that absorption is maximized in transitions 1 and 2 [13]. As embodied in [14], this partial filling can be achieved in different manners: 1) It can be achieved naturally, if the IB material exhibits a metallic band; 2) if IB material naturally presents a filled or empty band, compensation doping is necessary to, respectively, either depopulate or populate part of the IB states; 3 ) for an intrinsic IB material in which the IB states are naturally empty, it has been calculated that, under high light concentration, the photofilling of these states can sustain a useful population of electrons that allows high efficiencies to be achieved [15]; 4) regardless of the a priori population of the IB and the intended doping, it has been discussed that, if the IB material lies on the depletion region of the solar cell, the effective population of the IB states is likely to be ruled by their location inside this region [16]. The two-photon measurements reported in Section IV and the contribution of this process to other results, such as current-voltage characteristics, rely on any of these means to occur.

In an ideal IBSC, the absorption coefficients for the three gaps are assumed not to overlap, which means that the energy of an absorbed photon will be used always to cause the transition with largest possible energy so that intraband thermalization losses are reduced to their minimum. Therefore, if illuminated solely with subbandgap monochromatic light, an ideal IBSC in the short circuit would not produce photocurrent, since the two-photon absorption process, which is necessary to pump an electron from the VB to the CB, would not take place. Nonetheless, diverse mechanisms could make photocurrent extraction possible under monochromatic bandgap illumination. This will be explained in Section III. In any case, the production of subbandgap photocurrent (PC) in such an experiment gives information about the position of the IB, if present, and indirectly about the absorption of subbandgap photons.

In Fig. 2 (bottom), the simplified band diagram of an IBSC under operation is sketched. Three quasi-Fermi levels $\varepsilon_{\mathrm{Fe}}, \varepsilon_{\mathrm{Fh}}$, 
and $\varepsilon_{\mathrm{FIB}}$ are used to describe the electronic populations of the $\mathrm{CB}$, the VB, and the IB, respectively. The two emitters of the IBSC are made of conventional semiconductor and therefore only the use of $\varepsilon_{\mathrm{Fe}}$ and $\varepsilon_{\mathrm{Fh}}$ is appropriate. The output voltage of the cell is equal to $\left(\varepsilon_{\mathrm{Fe}}-\varepsilon_{\mathrm{Fh}}\right) / e$, where $e$ is the electron charge. The open-circuit voltage of this structure is therefore limited by $E_{G}$, as in a single-gap solar cell, and not by any of the two subbandgaps $E_{H}$ or $E_{L}$ [1], [17]. This phenomenon is commonly known as voltage preservation and is the second key operating principle of an IBSC.

As pointed out previously, an IB-material should present a characteristic luminescent spectrum. In operation, the existence of three distinct quasi-Fermi levels rules the intensity of the luminescent spectrum of an IBSC, which should reveal $E_{G}, E_{H}$, and $E_{L}$ if all transitions have a measurable radiative component.

\section{INTERMEDIATE BAND SOLAR CELL Characterization TECHNIQUES}

In this section, we describe the most common experimental techniques employed in IBSC characterization. Eight techniques are described, each one constituting a subsection. Techniques 1-5 are applied to IBSCs, while techniques 6-8 are applied to IB-materials. As a graphic example, one representative experimental result is included for each characterization technique.

\section{Subbandgap Spectral Response or Quantum Efficiency}

The production of photocurrent, expressed as spectral response (SR) or quantum efficiency $(\mathrm{QE})$, is probably the most reported result in IBSC characterization. This technique consists of resolving spectrally the photocurrent produced in the solar cell when illuminated under short-circuit conditions. A single-gap solar cell cannot exploit photons with energy lower, or wavelength higher, than that of the bandgap to produce current. The production of current due to subbandgap illumination in an IBSC gives therefore a strong evidence of the presence of intermediate states within the semiconductor bandgap.

In single-gap solar cells, it is not unusual to add a white light bias to the sample, in order that the $\mathrm{QE}$ be measured under conditions similar to 1-sun illumination. In the case of an IBSC, the two ways of measuring the QE, with or without light bias, may provide qualitatively different results, because of the multiphoton processes that are expected if broadband illumination is present. To date this experiment has been generally performed without light bias, which must be taken into account when interpreting the results.

As advanced in Section II, an ideal IBSC should not generate photocurrent when illuminated with monochromatic subbandgap light. However, three mechanisms can make it possible. First, if the absorption coefficients for transitions 1 and 2 overlap, a monochromatic beam of photons with energy higher than $E_{H}$ could produce both transitions [17], [18]. Second, even if only one of these two transitions is optically activated, impact ionization processes could lead to the consecution of the other, as an alternative to the missing optical transition [19]. Third, tunnel and thermal escape of carriers have been proven to allow transitions between the intermediate states and the $\mathrm{CB}$ in

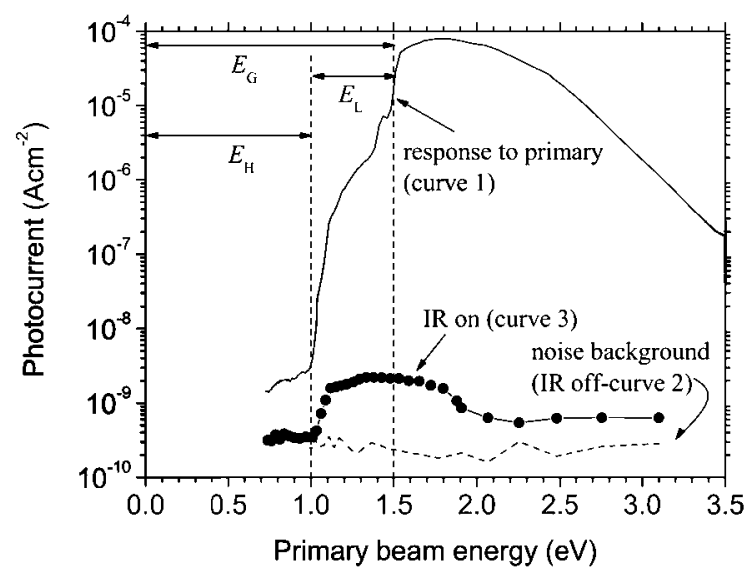

Fig. 3. Low-temperature spectral response and two-photon photocurrent of an InAs-GaAs QD-IBSC. Curve 1 represents the monochromatic spectral response of the sample. Subbandgap response is present for energies higher than $E_{H}$. Curve 3 represents the measured two-photon photocurrent, measured using the TPPC1 technique, which has its onset at $E_{H}$, as deduced by comparison with the SR measurement (curve 1). Reprinted with permission from [22], copyright 2006.

some IBSC prototypes [20]. This thermal escape may also be produced by thermal photons that are very abundant, and usually more than the light injected form an external source, at the energies between the IB states and the CB [21]. An IBSC device exhibiting any of these mechanisms is expected to have a lower potential efficiency than an IBSC with proper two-photon absorption, as described previously.

Fig. 3 shows the monochromatic spectral response of an InAsGaAs QD-IBSC, measured by Martí et al [22]. Contribution of subbandgap energy photons is clearly visible in the response of the IBSC sample (curve 1).

\section{Two-Photon Subbandgap Photocurrent}

The production of two-photon subbandgap photocurrent (TPPC) is a powerful experimental technique for demonstrating IBSC behavior. It was first proposed and verified in [22]. Since then, different results reporting this phenomenon have been published. However, unlike for the rest of experimental techniques employed, the TPPC characterization has been carried out in different manners. This complicates direct comparison between results. This is why in this review, we are going to distinguish among four different variations of the TPPC technique found in the literature.

The first technique, TPPC1, consists of spectrally resolving the photocurrent induced under short-circuit conditions (as in the SR measurement) with and without an additional infrared (IR) source. The IR source is filtered so that photons with energy higher than $E_{L}$, but none with energy above $E_{H}$, reach the sample (caution should be adopted with parasitic unwanted photons). The underlying idea is that, under primary subbandgap illumination with photons with energy higher than $E_{H}$, which will cause the first electronic transition, photons emitted by the IR source, with energy higher than $E_{L}$, will activate the second transition, enabling the extraction of photocurrent. The increase of photocurrent produced under the IR illumination is the TPPC. 
In TPPC1, the IR source is chopped, and the detection of the photocurrent is done with a lock-in amplifier, extracting thus only the component of the photocurrent due to the additional IR illumination.

The second technique, TPPC2, is a variation of TPPC1 in which the chopped light source is not the IR source but the primary light beam. Two measurements, at different times, are needed in this case: one with the IR source ON and another with the IR source OFF. The photocurrent due to the two-photon illumination is in this case obtained by subtracting the second measurement to the first.

The third technique, i.e., TPPC3, consists of measuring twice, at different times, the current-voltage $(I-V)$ characteristic of the device: first under one color illumination and then under twocolor illumination. The first color has energy higher than $E_{H}$ but lower than $E_{G}$ and the second has energy higher than $E_{L}$ but lower than $E_{H}$. In this case, an increase in the measured shortcircuit current resulting from the addition of the low energy beam is considered evidence of TPPC production.

The fourth technique, TPPC4, also requires two measurements at different times. First, the conventional SR of the device is measured, as previously described. Then, a laser beam with photons of enough energy to pump electrons from the VB to the IB is added, and the measurement is repeated. An increase of the $\mathrm{QE}$ for photon energies capable of promoting an electron from the IB to the CB is considered evidence of TPPC. The explanation for this is that the laser serves to populate the IB, which has then more electrons to be pumped to the $\mathrm{CB}$ by the primary beam.

Because it only requires one measurement, TPPC1 avoids errors associated with comparison of measurements at different times, which makes it more reliable that the other three to unmistakably reveal two-photon excitation processes. An improvement to TPPC1 would consist in making the IR light go through a monochromator, which would provide spectral resolution for transition 2 in Fig. 1. This would be irrefutable proof of two-photon photocurrent, revealing at the same time the value of $E_{L}$.

Fig. 3 shows the TPPC of an InAs/GaAs QD-IBSC measured at low temperature (LT) with the TPPC1 technique. Curve 3 represents the measured two-photon photocurrent, which has its onset at $E_{H}$, as deduced by comparison with the SR measurement (curve 1).

\section{Increase in Short-Circuit Current Under White Light Illumination}

An increase of the $J_{\mathrm{SC}}$ (usually detected by measuring the $J-V$ characteristic of the device under 1-sun illumination) of an IBSC with respect to its reference cell gives indirect evidence of the production of subbandgap photocurrent. Assuming that the photocurrent due to supra-bandgap illumination is the same in both cells, the increase of $J_{\mathrm{SC}}$ must then be due to subbandgap illumination. Note that the production of a larger photocurrent is a requisite for the IBSC exceeding the conversion efficiency of single-gap solar cells. Fig. 4 shows the $J-V$ characteristic of a GaAs reference solar cell and various InAs/GaAs QD-IBSC

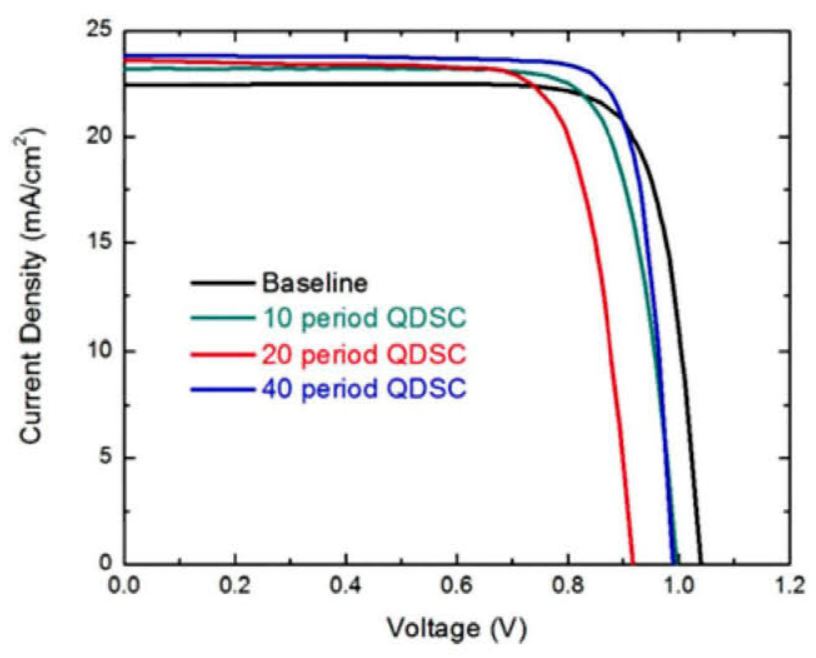

Fig. 4. $J-V$ measurement of a GaAs reference solar cell and various InAs/GaAs QD-IBSC prototypes with different number of QD layers. The $J_{\mathrm{SC}}$ of the IBSC exceeds that of the reference cell in all cases. Reprinted with permission from [23], (C) 2012.

prototypes with different number of QD layers, measured by Bailey et al [23]. The $J_{\mathrm{SC}}$ of the IBSC exceeds that of the reference cell in all cases.

A quick note on the relationship between the $\mathrm{QE}$ and the $J_{\mathrm{SC}}$ of a solar cell follows, which will allow us to better discuss and compare the results presented in Section IV. The short-circuit current of a single-gap solar cell can be calculated using the following equation [24]:

$$
J_{\mathrm{sc}}=e \int_{0}^{\lambda_{\mathrm{G}}} F_{\text {sun }}(\lambda) \mathrm{QE}(\lambda) d \lambda
$$

where $F_{\text {sun }}$ is the flux of photons reaching the cell from the sun, $\lambda$ is the wavelength of a given photon, and $\lambda_{G}$ is the wavelength corresponding to the bandgap of the solar cell. Note that the upper limit of the integral is unnecessary since for wavelengths higher (or energies smaller) than that of the bandgap, the absorbance of the solar cell is zero, as well as the QE. As stated before, current IBSC prototypes usually exhibit subbandgap QE; thus-accounting for the moment for monochromatic illumination only-the short-circuit current of an IBSC would be

$$
J_{\mathrm{sc}}=e \int_{0}^{\lambda_{\mathrm{H}}} F_{\text {sun }}(\lambda) \mathrm{QE}(\lambda) d \lambda
$$

where $\lambda_{H}$ is the maximum photon wavelength for which the $\mathrm{QE}$ has a finite value. The letter $\mathrm{H}$ has been chosen for the subindex to account for the fact that, in the majority of the reported $\mathrm{QE}$ results, this threshold wavelength is that of the subgap $E_{H}$. The integral in (2) can be readily split into two addends, giving rise to

$$
\begin{aligned}
J_{\mathrm{sc}}= & e\left(\int_{0}^{\lambda_{\mathrm{G}}} F_{\text {sun }}(\lambda) \mathrm{QE}(\lambda) d \lambda\right. \\
& \left.+\int_{\lambda_{G}}^{\lambda_{\mathrm{H}}} F_{\text {sun }}(\lambda) \mathrm{QE}(\lambda) d \lambda\right) .
\end{aligned}
$$




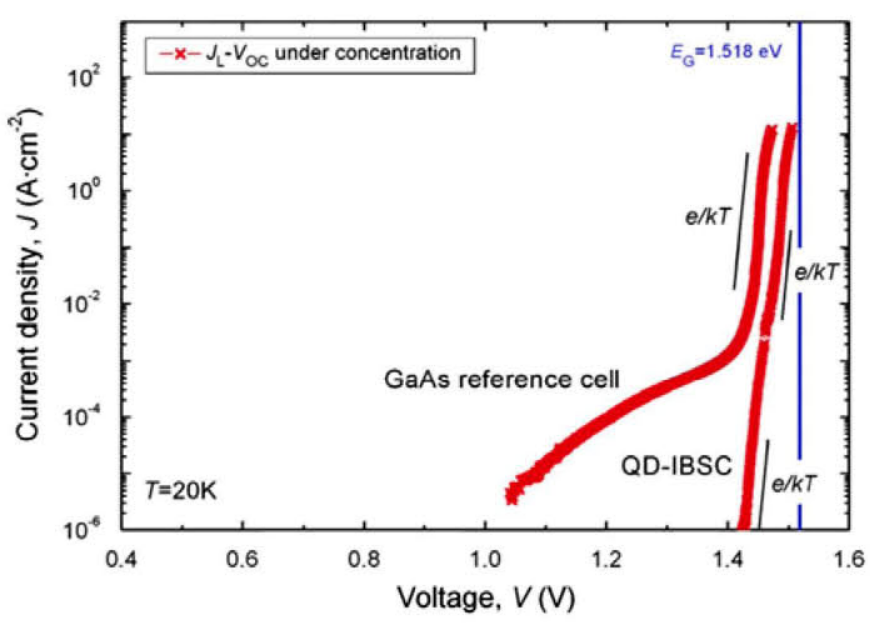

Fig. 5. $J_{L}-V_{\mathrm{OC}}$ measurement at LT of an InAs/GaAs QD-IBSC prototype and its reference cell. Both samples reach an open-circuit voltage close to the value of the bandgap of the GaAs divided by e. Reprinted from [25], (c) 2011, with permission from Elsevier.

The first addend coincides with (1). The second is the extra short-circuit current related to the presence of the IB. It is obvious, then, that the short-circuit current of an IBSC prototype can exceed that of its reference if there is indeed a subbandgap photocurrent and/or the integrated supra-bandgap QE is greater. Both $J-V$ and QE measurements should be presented always in pair, as they complement each other.

The previous analysis has been made neglecting the contribution of the two-photon photocurrent to $J_{\mathrm{SC}}$, and is therefore not valid for proper IBSCs. However, this contribution has been found to be very small, and sometimes only measurable at LT, in current IBSC prototypes (see Section IV). Therefore, the previous analysis results in a valid approximation for state-of-the art IBSC prototypes.

\section{Voltage Preservation}

As we define voltage preservation, it is the ability of an IBSC to achieve a $V_{\mathrm{OC}}$ higher that any of the two subbandgaps related to the IB and, under sufficiently high light concentration, to reach a photo-induced voltage close to $E_{G} / e$. As opposed to the $J_{\mathrm{SC}}$, the $V_{\mathrm{OC}}$ of an IBSC is not to be compared with that of its reference cell for voltage preservation to be verified. The only condition is that the output voltage is not limited by the presence of the IB, and one direct proof of that is to measure a voltage higher than $E_{H} / e$. Fig. 5 shows the photogenerated density current versus open-circuit voltage $\left(J_{L}-V_{O C}\right)$ curves at LT of an InAs/GaAs QD-IBSC prototype and its reference cell, measured by Linares et al [25]. Both samples reach an opencircuit voltage close to the value of the bandgap of the GaAs divided by $e$.

A voltage loss with respect to the reference cell under 1-sun illumination is actually expected even for an ideal IBSC [16], but this does not exclude voltage preservation to take place at higher light concentration. Some recent results show an extraordinary improvement of the $V_{\mathrm{OC}}$ in HMA-based IBSC prototypes with respect to its reference cell. These results will be commented on

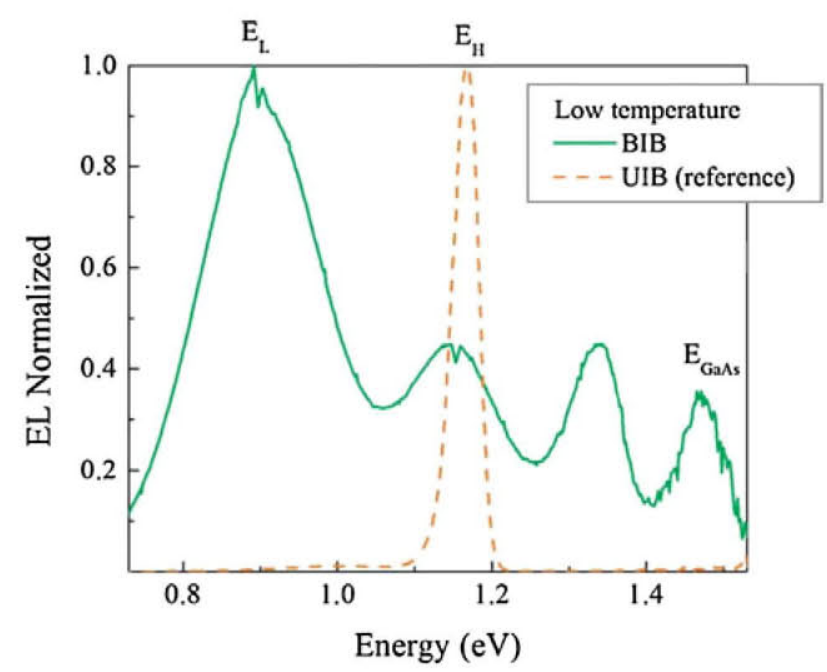

Fig. 6. EL measurement at RT of a GaAs:N IBSC prototype (green line, labeled BIB). The luminescence spectrum reveals emission at the energies of the three gaps $E_{G}, E_{H}$, and $E_{L}$. Reprinted with permission from [27], (C) 2011.

in Section IV, but let us now state that the structure used as a reference for those experiments does not adjust to the definition of a reference cell given in Section II.

\section{Electroluminescence}

The electroluminescence (EL) experiment consists in measuring the luminescent spectrum that results from the injection of current in a sample containing a p-n junction. As anticipated in Section II, three distinct luminescent peaks - one for each energy gap in the IB material-should be present in this spectrum. This emission, even if weak, must exist as a counterpart to the absorption of photons; this is known as the Shockley-Roosbreck relationship [26]. The presence of a luminescent peak related to any of the two subbandgaps $E_{H}$ or $E_{L}$ is a sufficient evidence of the existence of intermediate states that interact optically with the VB or the CB. Fig. 6 shows the EL spectra at room temperature (RT) of a GaAs:N IBSC prototype (green line, labeled BIB), measured by López et al. [27]. The luminescence spectrum reveals emission at the energies of the three gaps $E_{G}, E_{H}$, and $E_{L}$.

The luminescence spectrum of the IBSC can also be obtained by employing the photoluminescence characterization technique (see Section III-7). This is a contactless technique than can be applied to bare materials but can be employed in complete devices as well. However, it is worthwhile noting that the results obtained with both techniques may differ; in particular, the luminescence arising from the single-gap emitter may lead to the erroneous conclusion that there is a quasi-Fermi level split between the two bands separated by $E_{L}$, when there is not [28]. It is therefore preferred to use the EL technique for characterizing IBSCs.

\section{Subbandgap Absorption}

As indicated in Section II, an IB material should absorb subbandgap energy photons with energy higher than $E_{L}$ in 


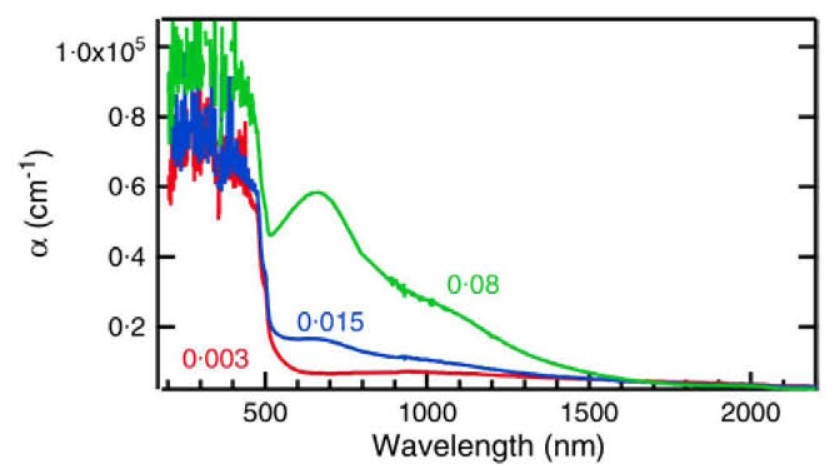

Fig. 7. Absorption spectra at $\mathrm{RT}$ of $\mathrm{CuGaS}_{2}: \mathrm{Fe}$ samples with different iron concentration. The absorption spectrum in the case of the sample with the highest iron concentration suggests two subbandgap edges. Reprinted with permission from [29], (C) 2011 John Wiley \& Sons, Ltd.

addition to suprabandgap photons. More precisely, the absorption coefficient of such material should present three singularities at the energy threshold of the three existing gaps $E_{G}, E_{H}$, and $E_{L}$. The experimental results evidencing subbandgap absorption presented in this section have been obtained by transmission, reflection, or some kind of photoresponse-related measurement.

The photoresponse measurements are often performed on complete devices but they do not properly correspond to an IBSC structure (namely p-IB material-n). Instead, these devices are, for example, photodetectors where the IB material is sandwiched between two conductive n-layers instead of $n$ - and a p-layers. Generally, the IB material is n-doped too with the aim that the IB is partially filled with electrons. Thus, when illuminated with photons able to promote electrons from the IB to the $\mathrm{CB}$, the IB material becomes more conductive, improving the overall device conductance. Fig. 7 shows the absorption spectra at RT of $\mathrm{CuGaS}_{2}: \mathrm{Fe}$ samples with different iron concentration, measured by Marsen et al [29]. The absorption spectrum in the case of the sample with the highest iron concentration suggests two subbandgap edges.

\section{Photoluminescence}

Photoluminescence (PL) has been extensively used in semiconductor research to identify the value of the energy bandgap, among many other purposes.

Regarding IB materials, this technique can be used also to identify the position of the IB within the bandgap. The technique consists basically in illuminating the semiconductor with suprabandgap light, which will be absorbed, and detect the luminescent photons reemitted by the material, resolving them spectrally. As pointed out in the introduction, three distinct luminescent peaks, at the energies $E_{G}, E_{H}$, and $E_{L}$, may be resolved in the spectrum of a proper IB material. Fig. 8 shows the PL spectrum at RT of a $\mathrm{CuInS}_{2}: \mathrm{Sn}$ and a $\mathrm{CuInS}_{2}$ samples, measured by Yang et al. [30]. The luminescence spectrum of the Sn-doped material reveals an additional peak that can be identified as originated from radiative IB $\rightarrow$ VB electronic relaxation.

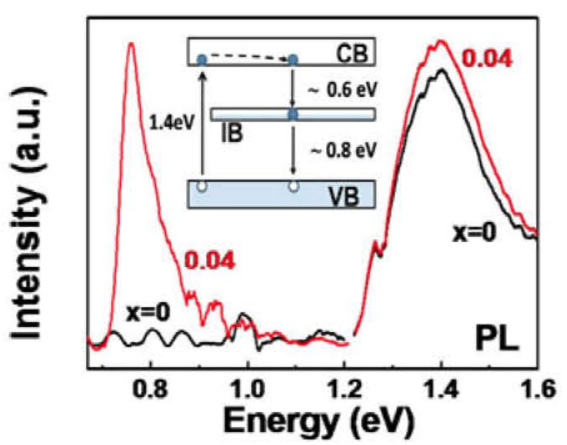

Fig. 8. PL measurement at RT of a CuInS $2: \mathrm{Sn}$ and a CuInS $\mathrm{C}_{2}$ samples. The luminescence spectrum of the Sn-doped material reveals an additional peak that can be related to radiative $\mathrm{IB} \rightarrow \mathrm{VB}$ electronic relaxation. Reprinted by permission from Macmillan Publishers Ltd: Scientific Reports, [30], (C) 2013.

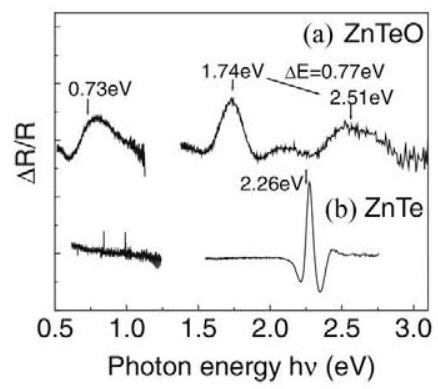

Fig. 9. PR measurement at RT of a $\mathrm{ZnTe}: \mathrm{O}$ and a $\mathrm{ZnTe}$ samples. Three signatures corresponding to the three gaps are present in the case of the $\mathrm{O}$ containing sample. Reprinted with permission from [31], (C) 2011.

\section{Photoreflectance}

Photoreflectance (PR) is a modulation spectroscopy characterization technique widely employed for characterizing bandto-band transitions in semiconductors. The PR technique consists of measuring the change in reflectivity of a sample by modulating an electric field acting on the sample. Usually, this electric field is the field existing at the surface of the sample, and its modulation is achieved by the absorption of photons from a modulated laser beam. Applied to the characterization of IB materials, the three possible optical transitions depicted in Fig. 1 could be identified.

Fig. 9 shows the PR spectrum at RT of a $\mathrm{ZnTe}: \mathrm{O}$ and a ZnTe sample, measured by Tanaka et al [31]. Three signatures corresponding to the three gaps are present in the case of the O-containing sample.

Applied to QD materials, this technique is capable of revealing the presence of the different confined levels introduced by the QDs and forming the IB. This is a key point, because the presence of multiple levels modifies the absorption and recombination properties of the material, which has an impact on the IBSC efficiency [32].

\section{INTERMEDIATE BAND SOLAR CELL EXPERIMENTAL RESULTS}

In this section, we will compile the most relevant experimental results related to the operation of IBSCs and the characterization of IB-materials. Since IB "solar cells" are the 
focus of this review, this description will be restricted to those materials for which manufacturing a device has also been possible at the time of writing these lines. For each of the three technological approaches, quantum dots, highly mismatched alloys, and bulk materials with deep-level impurities, we will review and discuss the experimental achievements obtained using the characterization techniques described in Section III.

A practical IBSC should behave as such at RT. However, in some of the experimental results presented herein, the samples had to be cooled down to cryogenic temperatures in order to demonstrate IB-related performance, due to the necessity of removing thermal escape. When this is the case, it will be indicated in the text.

When referring to a QD system, we will use the notation $X / Y$, where $\mathrm{X}$ is the QD material, and $\mathrm{Y}$ is the material of the matrix. When referring to HMAs, we will use the notation $\mathrm{X}$ : $\mathrm{Y}$, where $\mathrm{X}$ is the main alloy and $\mathrm{Y}$ is the element introduced in small quantities, responsible for the band anticrossing effect. When referring to a bulk material with DLI, we will use the notation $\mathrm{X}: \mathrm{Y}$, where $\mathrm{X}$ is the bulk material, and $\mathrm{Y}$ is the DLI. An element is placed in parentheses to indicate that it is sometimes, but not always, part of the studied material.

\section{A. Quantum Dots}

QDs have been the first and most studied candidate materials for implementing an IBSC. Most of QD-IBSC prototypes to date have been manufactured using the $\operatorname{In}(\mathrm{Ga}) \mathrm{As} / \mathrm{GaAs} \mathrm{QD}$ system. To tackle the problem of the accumulated strain in the QD-stack and improve the material quality, a small amount of $\mathrm{N}$ [33], P [34]-[36] or Sb [37] has been included in some cases in the host material. Although the bandgap distribution in this material is not optimal for an IBSC, this system was already technologically mature and, hence, the best candidate for testing the IB principles. This system served to demonstrate the operating principles of the IBSCs, and, encouraged by this advance, several groups worldwide decided to study other QD systems for its use in an IBSC.

1) Subbandgap Spectral Response or Quantum Efficiency: For In(Ga)As/GaAs QDs subbandgap, SR or QE has been reported by numerous groups [23], [33]-[42]. The GaSb/GaAs QD system has also been used in the fabrication of IBSCs. The SR of such devices is reported in [43]-[45] and shows clear subbandgap contribution. Recently, stacks of new QD systems using AlGaAs as the host material have been employed to manufacture complete IBSC devices. Reported QE measurements revealed the production of subbandgap photocurrent in InAs [46], [47] and GaAs [48] QD-based prototypes. Finally, subbandgap QE has also been demonstrated in GaAs quantum rings grown on AlGaAs [49].

The subbandgap QEs show different features that are usually identified as resulting from absorption in the wetting layer (WL) or in the QDs. The height of the QE at wavelengths corresponding to absorption in the WL is usually at least one order of magnitude higher that than of the QDs. The WL is generally seen as an extension of the $\mathrm{CB}$ (or VB), effectively reducing the bandgap $E_{G}$. Under this perspective, it is only the absorption in the QDs the one that counts for the extra photocurrent with voltage preservation that the IBSC exploits.

In general, the subbandgap response of the QD-IBSC is weak. This can be at least partially explained by the low QD density $\left(10^{10}-10^{11} \mathrm{~cm}^{-2}\right)$ and limited number of QD layers. In [50], QD-IBSCs with a stack of up to 50 QD layers were manufactured. The subbandgap $\mathrm{QE}$ was proven to increase with the number of QD layers. Recently, solar cells with up to 150 InGaAs/GaAs QD layers and QD stacks containing up to 400 layers have been manufactured [51], which shows that technological improvement toward IBSCs with a high density of QDs is in progress.

2) Two-Photon Subbandgap Photocurrent: For the InAs/ $\mathrm{Ga}(\mathrm{N})$ As case, there is a reported evidence of TPPC by the techniques TPPC1 [22] and TPPC2 [52]. In [22], the result was only obtained at LT, since at RT the thermal escape of carriers prevented the detection of TPPC. The issue of the thermal escape of carriers in InAs/GaAs QDs is well known, and it has been demonstrated that at RT the thermal escape of electrons from the IB to the CB is dominant [53], [54]. Although optical excitation of electrons from the IB to the CB is still possible, it occurs with a low probability, since most of them are thermally excited to the CB. That is the reason why quantum-dot infrared photodetectors (QDIPs) need to work at LT [55], [56], $260 \mathrm{~K}$ being the highest temperature at which infrared directivity has been reported in an $\operatorname{In}(\mathrm{Ga}) \mathrm{As} / \mathrm{GaAs}$ QDIP without high bandgap blocking barriers [57]. It is therefore remarkable that the InAs/GaNAs-based IBSC prototype reported in [52] exhibits TPPC at RT. One possibility is that it is due to the incorporation of $N$. It would be interesting, though, to repeat those experiments at lower temperatures, as well as with the technique TPPC1.

TPPC was also reported for the GaAs/AlGaAs system by the TPPC1 technique [48], again at LT.

3) Increase in Short-Circuit Current Under White Light Illumination: The additional subbandgap response in the In(Ga)As/Ga(N,P,Sb)As QD-IBSC prototypes mentioned in Section IV-A1 did not always lead to an increase in the $J_{\mathrm{SC}}$, because the suprabandgap response of the cell was degraded by the inclusion of the dots [58]. In particular, strain built-up can result in a degradation of the material quality in the front emitter of the cell. On the other hand, increase of the $J_{\mathrm{SC}}$ has been sometimes reported for this QD systems [23], [37], [38], [40], [42], [51] and for the GaSb/GaAs system [43], [45]. This is still not the case for the InAs/AlGaAs and GaAs/AlGaAs systems.

Remarks concerning some of these results must be made. As said in Section III, the increase in $J_{\mathrm{SC}}$ may be due to subbandgap, suprabandgap, or multiphoton photocurrent. The results reporting two-photon photocurrent in QD-based solar cells indicate that the efficiency of this process is low in current prototypes and sometimes only detectable at LT. Therefore, it is fair to assume that the contribution to the photocurrent of this process would be smaller than the other two. An increase in $J_{\mathrm{SC}}$ of a QD-IBSC should therefore be, to a high extent, explained by an enhancement of the QE. The integrated subbandgap QE should be comparable to the increase in $J_{\mathrm{SC}}$, if the suprabandgap QEs of both the IBSC and reference are similar. In most of the 
presented results, the increase of $J_{\mathrm{SC}}$ is less than $2 \mathrm{~mA} \cdot \mathrm{cm}^{-2}$, which can roughly be explained by integrating the subbangdap $\mathrm{QE}$ over the AM1.5G spectrum. In [51], $J_{\mathrm{SC}}$ increases up to $6 \mathrm{~mA} \cdot \mathrm{cm}^{-2}$. This large increase is explained partly by the integrated subbandgap $\mathrm{QE}$ and partly because the supra-bandgap $\mathrm{QE}$ is somewhat improved in the IBSC prototype. Whether this improvement is due to the QDs or simply to a better quality of the grown material is not discussed.

On the other hand, $J_{\mathrm{SC}}$ results presented in [40] cannot be explained in terms of the integrated QE. In this study, it is shown an increase in $J_{\mathrm{SC}}$ of more than $9 \mathrm{~mA} \cdot \mathrm{cm}^{-2}$; however, the reported subbandgap SR, although in relative units, is clearly too weak to be responsible for such an increase. Unfortunately, the suprabandgap SR is not shown in their study. Indeed twophoton processes, which cannot be detected in monochromatic QE measurement, can lead to enhanced photocurrent, but it is worthwhile remembering that the sequential two-photon excitation of carriers follows a "series-like" path. This means that the smallest of the two absorptions limits the extra photocurrent; they are not to be added up. So, in order to achieve a $9 \mathrm{~mA} \cdot \mathrm{cm}^{-2}$ increase resulting from two-photon processes, both the absorption coefficients of transitions 1 and 2 in Fig. 1 should be as high as to lead to this increase in photocurrent under the AM1.5G spectrum with 20 layers of QDs. However, a close look to the absorption and photocurrent measurements gathered in this review reveal this situation to be unlikely. In any case, we suggest that TPPC measurements could shed light on the discrepancies between the reported $\mathrm{QE}$ and $J_{\mathrm{SC}}$. It is worth noting that, unlike in many other works, the studied IBSC prototypes are n-doped in the QD-region, and it is shown that the increase in $J_{\mathrm{SC}}$ increases with the doping. It is still unclear what the effect of high doping levels in the QD-region is, owing to a lack of different corroborated experimental results, but it is certainly a subject that deserves further study.

Analogously, the $5.7 \mathrm{~mA} \cdot \mathrm{cm}^{-2}$ increase reported in [45] is hardly attributable to the subbandgap QE, especially since the suprbandgap response is shown to be degraded in the QD samples. Moreover, the $\mathrm{QE}$ of the GaAs reference cell presented in this study is below 0.3 for all photon energies; however, $J_{\mathrm{SC}}$ of such a device is $15 \mathrm{~mA} \cdot \mathrm{cm}^{-2}$. This data seems to reveal a contradiction, since record GaAs solar cells, with $\mathrm{QE}$ close to unity, present a $J_{\mathrm{SC}}$ lower than $30 \mathrm{~mA} \cdot \mathrm{cm}^{-2}$ [59].

4) Voltage Preservation: The QD-IBSC prototypes present consistently a smaller $V_{O C}$ than the reference cell. As pointed out in Section III, a voltage loss is predicted even in ideal IBSCs, where voltage preservation is achieved under concentrated light. However, the measured voltage loss in the studied devices is generally higher than expected, suggesting an increase in nonradiative recombination in the QD stack.

Voltage preservation has been demonstrated in InAs/GaAs QD-IBSC prototypes in two different ways: by illuminating the cell with a suprabandgap energy laser and measuring the $V_{\mathrm{OC}}$ of the device [60], and by obtaining the $J_{L}-V_{\mathrm{OC}}$ characteristic of the device using white light as explained in [25]. In both cases, the $V_{\mathrm{OC}}$ of the IBSCs reached values close to the bandagap of the GaAs, which is well above the measured value of $E_{H}$ bandgap. For this to happen, it was necessary to lower the tem- perature of the samples in order to remove the thermal escape of carriers and allow the quasi-Fermi levels of the IB and the CB to split apart (see Section IV-A5) for further information on this point).

5) Electroluminescece: In [28], the EL spectra of InAs/GaAs QD-IBSC prototypes were presented at different temperatures. At RT, one luminescent peak was detected at the energy $E_{H}$. At sufficiently low temperatures, where thermal carrier escape is inhibited, an additional peak, at the energy $E_{G}$, was simultaneously detected. It has been sometimes argued that the presence of this second peak, with an intensity unusually high, evidences the existence of three distinct quasi Fermi levels [61]. Some other authors have argued that the height of this peak could be alternatively explained by sample heating [62]. In any case, the energy of the emission related to $E_{L}$, which would correspond to the third expected peak, remained outside the range of measurements.

6) Subbandgap Absorption: In(Ga)As/(Al)GaAs QDs are a well-known technology widely studied also outside the IBSC framework. Subbandgap absorption has been demonstrated in InAs/GaAs QDs by transmission measurements revealing transitions from the IB to the CB [63], [64] at LT and from the VB to the IB [65], and by photoresponse measurements, revealing both transitions at LT [56]. Evidence of the electronic transition from the IB to the $\mathrm{CB}$ was also reported for the InAs/AlGaAs system by transmission measurements [64] at LT. The GaAs/AlGaAs QD system has been studied in the framework of the IB theory. Photoresponse related to the $\mathrm{VB} \rightarrow \mathrm{IB}$ and the $\mathrm{IB} \rightarrow \mathrm{CB}$ transitions - the latter only at LT - has also been reported [66] for this material.

7) Photoluminescence: InAs QDs have been extensively characterized by PL measurements out of the scope of the IB approach. Radiative electronic relaxation from the IB to the VB has been detected for the InAs/GaAs system [56], [63], [64], [67], [68] and for the InAs/AlGaAs system [64], [67], [69]. It must be noticed, however, that no luminescence that can be attributed to photons arising from the relaxation of electrons from the $\mathrm{CB}$ to the IB has been reported yet. PL measurements have also revealed $\mathrm{IB} \rightarrow \mathrm{VB}$ recombination in GaAs/AlGaAs QDs outside [70] and within [49], [66] the framework on IBSC research. Emission related to the presence of the IB has been reported for the GaSb/GaAs system [44], [45], [71]. Note that, contrarily to the rest of QD materials presented herein, this system has a type II alignment in the $\mathrm{CB}$, and the IB is formed out of hole confined states in the VB of the QD [72], with the IB sitting closer to the VB than to the $\mathrm{CB}$. Therefore, the luminescence reported in this study is due to $\mathrm{CB} \rightarrow \mathrm{IB}$ relaxation but still corresponds to the larger of the two subbandgaps $E_{H}$.

In [73], PL measurements demonstrated that the position of the IB in a QD material can be tuned by modifying the size and shape of the dot. This could be a key factor for IBSC implementation, as the conversion efficiency of these devices depends on both the bandgap of the host and the position of the IB.

8) Photoreflectance: PR features related to the VB $\rightarrow$ IB transition have been reported in InAs/GaAs QD [68] and in InAs/Ga(N)As QD-IBSC structures [74], [75]. Subbandgap 
signatures attributed to the ground states of the QDs have been recently measured in the InAs/AlGaAs system [75]. No sign of the IB $\rightarrow$ CB transition has been reported for any of these samples.

\section{B. Highly Mismatched Alloys}

Over the last five years, different HMAs have been used to implement IBSC. Although the discovery of the special of properties of such material is recent, the knowledge gained through QD-IBSC research has enabled the achievement of promising experimental results.

It has to be precised that the benchmark cells found in the literature that are used to compare IBSC performance for this group of materials cannot, in some cases, be considered as reference cells as we have defined it in this study. These benchmark cells still maintain the IB-region instead of replacing it by a conventional semiconductor [27], [76]-[78]. What differentiates the benchmark and the IBSC sample is the presence of a blocking layer that disconnects electronically the IB from the CB in the IBSC samples.

1) Subbandgap Spectral Response Or Quantum Efficiency: The production of subbandgap QE has been reported for $\mathrm{ZnTe:O}$ [31], [78], [79] and $\mathrm{Ga}(\mathrm{P}, \mathrm{Sb}) \mathrm{As:N}$ [27], [76], [77]-based IBSC prototypes. The analysis of the QE comparison between benchmark and IBSC prototype is more intricate than for the case of using a reference cell. In [27], the QE of both GaAs: $N$ cells, without and with blocking layer, was first reported. The subbandgap QE decreases strongly in the sample with a blocking layer. This proves the effective electronic blockage between the $\mathrm{IB}$ and the $\mathrm{CB}$ : electrons pumped from the VB to the IB find it more difficult to escape to the CB. The suprabandgap QE of this sample is low; its value is roughly the same as the subbandgap $\mathrm{QE}$, which, as has just been said, was strongly reduced. One possible explanation for this is that the absorption coefficient of the $\mathrm{VB} \rightarrow \mathrm{CB}$ transition is small in absolute terms or smaller than the absorption coefficient at those energies for the $\mathrm{VB} \rightarrow$ IB transition. The QEs reported later on in [76] and [77] show different features. In these works, the subbandgap QE barely varies between the blocked and non-blocked devices. In addition to that, the supra-bandgap QE is much higher than in [27]. In [78], a reduction in the subbandgap QE of the blocked device is reported for a $\mathrm{ZnTe}$ O-based prototype.

The structure of these IBSCs is not yet optimized, and thus, their maximum QE is not close to unity, but it is significant that the subbandgap $\mathrm{QE}$, for energies above $E_{H}$ is, in most cases, greater than 0.1 for the unblocked device, which indicates that the absorption coefficient for the VB $\rightarrow$ IB transition is high enough for photovoltaic applications.

2) Two-Photon Subbandgap Photocurrent: In devices made of ZnTe:O, two-photon photocurrent has been reported using techniques TPPC2 [78], TPPC3 [31], [79], and TPPC4 [78]. In IBSC prototypes fabricated using $\mathrm{Ga}(\mathrm{P}, \mathrm{Sb}) \mathrm{As}$ : N for the IBmaterial, the production of TPPC has been reported by the TPPC2 technique [76], [77]. All these results have been obtained at RT.
As previously commented for the TPPC measured at RT for QD-based prototypes, it would be interesting to perform TPPC1 measurements on these devices at different temperatures to gain a more accurate insight on the two-photon processes which take place.

3) Increase in the Short-Circuit Current Under White Light Illumination: The increase of $J_{\mathrm{SC}}$ as compared with its reference cell as defined herein has only been reported in [79], for a $\mathrm{ZnTe:O}$ IBSC prototype. In [76], a proper reference cell is manufactured, but unfortunately the $J-V$ curve of this device is not shown for comparison.

It has been found that the presence of the blocking layer results in a reduction in $J_{\mathrm{SC}}$, which supports the premise that it disconnects the IB from the CB. In [27], the $J-V$ characteristics of the blocked and unblocked devices are presented. The $J_{\mathrm{SC}}$ of the blocked device is four times smaller than that of the reference. These results suggest that the $\mathrm{IB} \rightarrow \mathrm{CB}$ absorption is weak, and multiphoton processes barely contribute to the photocurrent. In [76], the benchmark cell presents $J_{\mathrm{SC}}$, under an illumination equivalent to 30 suns, five times higher than the sample containing the blocking layer. However, the QE results of these devices are very similar and do not explain this difference.

Efforts need to be made in finding the appropriate materials for fabricating proper reference cells so that a conclusive comparison between $J_{S C}$ 's and $V_{O C}$ 's (see Section IV-B4) can be made.

4) Voltage Preservation: No evidence of this phenomenon has been reported for this group of materials, for in all cases the measured $V_{\mathrm{OC}}$ is smaller than the obtained value for $E_{H}$.

The measured $V_{\mathrm{OC}}$ of the samples containing blocking layers was in all cases higher than that of the benchmark cells [27], [76], [78]. It is argued that this is a consequence of the disconnection between the IB and the CB and proves the proper IBSC operation. In [76], a proper reference cell is manufactured, and some results, such as TPPC, of this device are presented, but its $J-V$ characteristic is lacking. We emphasize that current and voltage comparison with a conventional reference cell is advisable to analyze the benefits and drawbacks of the presence of the IB material. Comparison with a proper reference cell is made in [79]. The results show a voltage loss in the IBSC prototype, as was the case for the QD-based devices.

5) Electroluminescece: In [27], GaAs:N was used to manufacture a complete IBSC device. It must be remarked that the EL spectrum of this device showed emission peaks attributable to the three interband transitions at RT. A fourth peak at an energy higher than $E_{H}$ but lower than $E_{G}$ is also identified in the spectrum. It was said to arise from the radiative recombination related to defects in the heavily doped n-GaAs substrate.

6) Subbandgap Absorption: The two subbandgap transitions have recently been verified for $\mathrm{ZnTe}$ :O by means of transmission and reflection measurements. Absorption from the VB to the IB was first demonstrated in [31]. In [80], the transition from the IB to the $\mathrm{CB}$, in addition to that from the VB to the IB, was experimentally verified for this material. It should be remarked that all these results were obtained at RT. Subbandgap absorption has also been reported for the diluted nitride GaPAs:N at RT [81]. In this case, however, only one subbandgap 
absorption edge, corresponding to the $\mathrm{VB} \rightarrow \mathrm{IB}$ transition, was detected.

7) Photoluminescence: IB $\rightarrow$ VB radiative recombination has been reported at RT in ZnTe:O [79] and GaPAs:N [81]. So far, no evidence of $\mathrm{CB} \rightarrow \mathrm{IB}$ luminescence has been reported for these materials.

8) Photoreflectance: Evidence of PR signatures related to intermediate states has been reported for ZnTe:O samples at RT [31]. It has to be remarked that the three possible interband transitions were identified. IB-related PR features have also been found in $\mathrm{Ga}(\mathrm{Sb}, \mathrm{P}) \mathrm{As}: \mathrm{N}$ at RT [27], [76], [77], [81]. In this case, only evidence of $\mathrm{VB} \rightarrow \mathrm{IB}$ transitions (in addition to $\mathrm{VB} \rightarrow$ CB) was reported.

As demonstrated in [82] by PR measurements, the incorporation of $\mathrm{N}$ and $\mathrm{P}$ in GaAs give a double degree of flexibility to tune the main bandgap of the alloy, as well as the position of the IB, which, as mentioned for the QD approach, may be a key factor for achieving efficient IBSC.

\section{Bulk Materials With Deep-Level Impurities}

This family of materials is the least investigated one so far, probably resulting from the technological difficulty involving the need of introducing a very high density of impurities [4], which usually degrades the quality and electronic properties of the host material.

1) Subbandgap Spectral Response or Quantum Efficiency: In [83], Ti-implanted GaAs was used as IB-material to attempt IBSC prototypes. Subbandgap QE was reported for these GaAs:Ti devices. We must point out that, in this particular case, subbandgap response was also detected in the reference cell. It is discussed that, in this case, the below bandgap response might be due to intermediate states originated from defects in the GaAs grown at lower than optimal temperature.

Another material used to fabricate IBSC prototypes is GaN:Mn [84]. It has to be emphasized that the SR measurements revealed two subbandgap edges, suggesting the value of $E_{L}$ and $E_{H}$ thresholds. These measurements were carried out biasing the devices at $-2 \mathrm{~V}$ and not under short-circuit conditions. DLI have also been introduced in chalcopyrites for its use in IBSCs. In this respect, subbandgap PC was reported for $\mathrm{CuGaS}_{2}: \mathrm{Fe}$ [29].

Similarly to the QD approach, the subbandgap response was found to be, in general, much weaker than the suprabandgap QE.

2) Two-Photon Subbandgap Photocurrent: So far, no evidence of TPPC has been reported for this group of materials.

3) Increase in the Short-Circuit Current Under White Light Illumination: Only Sn-doped $\mathrm{CuInS}_{2}$ has led to this result. In [30], films of $\mathrm{CuInS}_{2}$ and $\mathrm{CuInS}_{2}: \mathrm{Sn}$ were assembled into photoelectrochemical cells to analyze their IBSC behavior. Such an IB device presented higher $J_{\mathrm{SC}}$ than its reference cell.

4) Voltage Preservation: The preservation of the voltage was demonstrated in a GaAs:Ti IBSC prototype by obtaining the $J_{L}-V_{\mathrm{OC}}$ characteristic under concentrated white light illumination [83]. In this case, it was also necessary to lower the temperature.
There are few results comparing the $V_{\mathrm{OC}}$ of an IBSC based on bulk with DLI compared with a reference cell. In [29], the $\mathrm{CuGaS}_{2}: \mathrm{Fe}$ IBSC prototypes present voltage losses that increase with $\mathrm{Fe}$ content. In [85], the $V_{\mathrm{OC}}$ is found to increase in the CuInS2:Ti-based prototypes, but this result is attributed to the presence of a $\mathrm{TiO}_{2}$ interlayer and is therefore not related to the IB.

5) Electroluminescece: No report of IB-related electroluminescence results has been made for this group of materials.

6) Subbandgap Absorption: Two subbandgap absorption edges, in addition to the main bandgap edge, have been measured in GaN:Mn [84], as well as in $\mathrm{GaN}: \mathrm{Cr}$ [86]. In the case of the Cr-doped samples, the fundamental bandgap of the $\mathrm{GaN}$ was found to shrink with $\mathrm{Cr}$ incorporation. IB-related absorption was also reported for the chalcopyrites hosts $\mathrm{CuGaS}_{2}$ and $\mathrm{CuInS}_{2}$. Two additional subbandgap absorption edges were detected by transmission measurements in $\mathrm{CuGaS}_{2}$ : Fe at RT [29]. Subbandgap absorption at RT was also measured in $\mathrm{CuGaS}_{2}: \mathrm{Sn}$ and $\mathrm{CuInS}_{2}: \mathrm{Sn}$ [30]. For these Sn-doped materials, no absorption signature appears at the energy of the bandgap. Instead, this absorption edge is red-shifted with increasing Sn concentration. It is argued that this effect, together with the appearance of another absorption edge at lower energy, is proof of the presence of the IB.

We want to emphasize that for all these materials, subbandgap absorption attributable to $\mathrm{VB} \rightarrow \mathrm{IB}$ and $\mathrm{IB} \rightarrow \mathrm{CB}$ transitions was detected at RT.

7) Photoluminescence: PL measurements performed at RT revealed additional IB $\rightarrow$ VB related emission in $\mathrm{CuInS}_{2}: \mathrm{Sn}$ [30], as compared with bare $\mathrm{CuInS}_{2}$.

8) Photoreflectance: Very recently, subbandgap PR signatures related to transitions from the VB to deep-level states were measured in GaAs:Ti samples [83].

\section{INTERMEDIATE BAND SOLAR CELl EXPERIMENTAL RECORD SUMMARY TABLE}

In this Section, we present Table I, which relates the various experimental tests that revealed IB phenomena to the IB materials used in IBSC. If reported experimental evidence exists, it is referenced. A blank case appears otherwise.

\section{CONCLUSION}

In the last decade, it has been possible to demonstrate the IBSC operating principles and verify the influence of the intermediate states in the optical and electrical properties of IBSCs. We have described here some IB-related phenomena that can be experimentally verified and have presented a compilation of reported results that are consistent with the IB theory, providing the reader with an updated IBSC experimental record. Due to the relative novelty of this concept, special care must be taken when analyzing the results obtained using classical semiconductor or solar-cell characterization techniques.

So far, quantum dots are the most widely employed approach to fabricate an IBSC and they have been used first to demonstrate IBSC operation but other candidate technologies, such as HMAs 
TABLE I

INTERMEDIATE BAND SOLAR CELl EXPERIMENTAL RECORd SuMMARY TABLE

\begin{tabular}{|c|c|c|c|c|c|c|c|c|c|}
\hline & & \multicolumn{4}{|c|}{ Sub-bandgap transitions } & \multicolumn{3}{|c|}{ Extra-photocurrent } & \multirow{2}{*}{$\begin{array}{l}\text { Voltage Preservation } \\
\qquad I_{\mathrm{L}}-V_{\propto C} \text { or } J-V\end{array}$} \\
\hline & $\overbrace{\text { Material }}^{\text {Experimental }}$ & Absorption ${ }^{\mathrm{a}}$ & PR & PL & EL & $\begin{array}{l}\text { Sub-bandgap } \\
\text { SR or QE }\end{array}$ & $\underset{\text { increase }}{J \text { sc }}$ & TPPC & \\
\hline \multirow{4}{*}{ QD } & $\operatorname{In}(\mathrm{Ga}) \mathbf{A s} / \mathrm{Ga}(\mathbf{N}, \mathrm{P}, \mathrm{Sb}) \mathbf{A s}$ & {$[56,63-65]^{e}$} & {$[68,74,75]$} & {$[56,63,64,67,68,73]$} & {$[28,61]^{b, e}$} & {$[23,33-42,50,51]$} & {$[23,37,38,40,42,51]$} & {$[22,52]^{e}$} & {$[25,60]^{\mathrm{b}, \mathrm{e}}$} \\
\hline & $\mathrm{GaSb} / \mathrm{GaAs}$ & & & {$[44,45,71]$} & & [43-45] & {$[43,45]$} & & \\
\hline & InAs/AlGaAs & [64] & [75] & {$[64,67,69]$} & & {$[46,47]$} & & & \\
\hline & $\mathrm{GaAs} / \mathrm{AlGaAs}$ & {$[66]^{e}$} & & {$[49,66,70]$} & & {$[48,49]$} & & {$[48]^{e}$} & \\
\hline \multirow{2}{*}{ HMA } & ZnTe:O & {$[31,80]$} & [31] & [79] & & {$[31,78,79]$} & [79] & {$[31,78,79]$} & \\
\hline & $\mathrm{Ga}(\mathrm{P}, \mathrm{Sb}) \mathrm{As}: \mathrm{N}$ & [81] & {$[27,76,77,81,82]$} & [81] & [27] & {$[27,76,77]$} & & {$[76,77]$} & \\
\hline \multirow{4}{*}{$\begin{array}{c}\text { Bulk } \\
\text { with DLI }\end{array}$} & $\mathrm{GaN}: \mathrm{Cr}, \mathrm{Mn}$ & {$[84,86]$} & & & & {$[84]^{d}$} & & & \\
\hline & GaAs:Ti & & [83] & & & [83] & & & {$[83]^{e}$} \\
\hline & $\mathrm{CuGaS2:Sn,Fe}$ & {$[29,30]$} & & & & {$[29]^{c}$} & & & \\
\hline & CuInS2:Sn & [30] & & [30] & & & [30] & & \\
\hline & & \multicolumn{3}{|c|}{ On IB material } & \multicolumn{5}{|c|}{ On IBSC prototype } \\
\hline
\end{tabular}

a By transmission, reflectance or photoresponse measurements.

bonly in pure InAs/GaAs QDs.

'Only with Fe.

'Only with Mn.

All or part of the results were only obtained at cryogenic temperatures

or bulk semiconductor material with deep-level impurities, have recently also been used to verify IB-related behavior.

Regarding the characterization techniques, absorption and spectral response are often employed, whereas results of voltage preservation, two-photon subbandgap photocurrent and electroluminescence measurements are still missing for many of the studied materials.

\section{ACKNOWLEDGMENT}

The authors would like to thank the anonymous reviewers for their useful critics and suggestions.

\section{REFERENCES}

[1] A. Luque and A. Martí, "Increasing the efficiency of ideal solar cells by photon induced transitions at intermediate levels," Phys. Rev. Lett., vol. 78, pp. 5014-5017, 1997.

[2] A. Martí, L. Cuadra, and A. Luque, "Quantum dot intermediate band solar cell," in Proc. 28th Photovoltaic Spec. Conf., 2000, pp. 940-943.

[3] W. Shan, W. Walukiewicz, J. W. Ager, III, E. E. Haller, J. F. Geisz, D. J. Friedman, J. M. Olson, and S. R. Kurtz, "Band anticrossing in GaInNAs alloys," Phys. Rev. Lett., vol. 82, pp. 1221-1224, 1999.

[4] A. Luque, A. Martí, E. Antolín, and C. Tablero, "Intermediate bands versus levels in non-radiative recombination," Physica B, Condensed Matter, vol. 382, pp. 320-327, 2006.

[5] A. Luque, A. Martí, and C. Stanley, "Understanding intermediate-band solar cells," Nat. Photon., vol. 6, pp. 146-152, 2012.

[6] A. Luque and A. Marti, "The intermediate band solar cell: Progress toward the realization of an attractive concept," Adv. Mater, vol. 22, pp. 160-174, Jan. 2010.

[7] A. Martí, E. Antolín, P. García-Linares, I. Ramiro, I. Artacho, E. López, E. Hernández, M. J. Mendes, A. Mellor, I. Tobías, D. Fuertes Marrón, C. Tablero, A. B. Cristóbal, C. G. Bailey, M. Gonzalez, M. Yakes, M. P. Lumb, R. Walters, and A. Luque, "Six not so easy pieces in intermediate band solar cell research," in Proc. SPIE OPTO, 2013, pp. $86200 \mathrm{~J}-1-86200 \mathrm{~J}-11$.
[8] A. Martí, E. Antolín, P. G. Linares, and A. Luque, "Understanding experimental characterization of intermediate band solar cells,"J. Mater. Chem., vol. 22, pp. 22832-22839, 2012.

[9] E. Antolín, A. Marti, C. Stanley, C. Farmer, E. Cánovas, N. López, P. Linares, and A. Luque, "Low temperature characterization of the photocurrent produced by two-photon transitions in a quantum dot intermediate band solar cell," Thin Solid Films, vol. 516, pp. 6919-6923, 2008.

[10] P. G. Linares, A. Martí, E. Antolín, I. Ramiro, E. Lopez, C. D. Farmer, C. R. Stanley, and A. Luque, "Low-Temperature concentrated light characterization applied to intermediate band solar cells," IEEE J. Photovoltaics, vol. 3, no. 2, pp. 753-761, Apr. 2013.

[11] W. Shockley and H. J. Queisser, "Detailed balance limit of efficiency of p-n junction solar cells," J. Appl. Phys., vol. 32, pp. 510-519, 1961

[12] N. J. Ekins-Daukes, C. B. Honsberg, and M. Yamaguchi, "Signature of intermediate band materials from luminescence measurements," in Proc. Photovoltaic Spec. Conf., 2005, pp. 49-54.

[13] A. Martí, L. Cuadra, and A. Luque, "Partial filling of a quantum dot intermediate band for solar cells," IEEE Trans. Electron Devices., vol. 48, no. 10, pp. 2394-2399, Oct. 2001.

[14] A. Martí and A. Luque, "Fundamentals of Intermediate Band Solar Cells," in Next Generation of Photovoltaics: New Concepts, A. B. Cristóbal, A. Martí, and A. Luque, Eds. Berlin, Germany: Springer, 2012.

[15] R. Strandberg and T. W. Reenaas, "Photofilling of intermediate bands," $J$. Appl. Phys., vol. 105, pp. 124512-1-124512-8, 2009.

[16] A. Martí, E. Antolín, E. Cánovas, N. López, P. G. Linares, A. Luque, C. R. Stanley, and C. D. Farmer, "Elements of the design and analysis of quantum-dot intermediate band solar cells," Thin Solid Films, vol. 516, pp. 6716-6722, 2008.

[17] A. Luque and A. Martí, "A metallic intermediate band high efficiency solar cell," Progress Photovoltaics, Res. Appl., vol. 9, pp. 73-86, 2001.

[18] L. Cuadra, A. Martí, and A. Luque, "Influence of the overlap between the absorption coefficients on the efficiency of the intermediate band solar cell," IEEE Trans. Electron Devices., vol. 51, no. 6, pp. 1002-1007, Jun. 2004.

[19] A. Luque, A. Martí, and L. Cuadra, "Impact-ionization-assisted intermediate band solar cell," IEEE Trans. Electron Devices., vol. 50, no. 2, pp. 447-454, Feb. 2003.

[20] E. Antolín, A. Martí, C. D. Farmer, P. G. Linares, E. Hernández, A. M. Sánchez, T. Ben, S. I. Molina, C. R. Stanley, and A. Luque, "Reducing carrier escape in the InAs/GaAs quantum dot intermediate band solar cell," J. Appl. Phys., vol. 108, pp. 064513-1-064513-7, 2010. 
[21] A. Luque, A. Martí, E. Antolín, P. G. Linares, I. Tobías, and I. Ramiro, "Radiative thermal escape in intermediate band solar cells," AIP Adv, vol. 1, pp. 022125-1-022125-6, 2011.

[22] A. Marti, E. Antolin, C. R. Stanley, C. D. Farmer, N. Lopez, P. Diaz, E. Canovas, P. G. Linares, and A. Luque, "Production of photocurrent due to intermediate-to-conduction-band transitions: A demonstration of a key operating principle of the intermediate-band solar cell," Phys. Rev. Lett., vol. 97, pp. 247701-1-247701-4, 2006.

[23] C. G. Bailey, D. V. Forbes, S. J. Polly, Z. S. Bittner, Y. Dai, C. Mackos, R. P. Raffaelle, and S. M. Hubbard, "Open-circuit voltage improvement of InAs/GaAs quantum-dot solar cells using reduced InAs coverage," IEEE J. Photovoltaics, vol. 2, no. 3, pp. 269-275, Jul. 2012.

[24] H. J. Hovel, "Solar cells," in Semiconductors and Semimetals. vol. 11, New York, NY, USA: Academic, 1975.

[25] P. G. Linares, A. Martí, E. Antolín, C. D. Farmer, I. Ramiro, C. R. Stanley, and A. Luque, "Voltage recovery in intermediate band solar cells," Sol. Energy Mater. Sol. Cells, vol. 98, pp. 240-244, 2011.

[26] W. Van Roosbroeck and W. Shockley, "Photon-radiative recombination of electrons and holes in germanium," Phys. Rev., vol. 94, pp. 1558-1560, 1954.

[27] N. Lopez, L. A. Reichertz, K. M. Yu, K. Campman, and W. Walukiewicz, "Engineering the electronic band structure for multiband solar cells," Phys. Rev. Lett., vol. 106, p. 4, Jan. 2011.

[28] I. Ramiro, E. Antolín, P. G. Linares, E. Hernández, A. Martí, A. Luque, C. D. Farmer, and C. R. Stanley, "Application of photoluminescence and electroluminescence techniques to the characterization of intermediate band solar cells," Energy Procedia, vol. 10, pp. 117-121, 2011.

[29] B. Marsen, S. Klemz, T. Unold, and H.-W. Schock, "Investigation of the sub-bandgap photoresponse in $\mathrm{CuGaS2}: \mathrm{Fe}$ for intermediate band solar cells," Progress Photovoltaics, Res. Appl., vol. 20, pp. 625-629, 2012.

[30] C. Yang, M. Qin, Y. Wang, D. Wan, F. Huang, and J. Lin, "Observation of an intermediate band in sn-doped chalcopyrites with wide-spectrum solar response," Sci. Rep., vol. 3, pp. 1286-1-1286-7, 2013.

[31] T. Tanaka, K. M. Yu, A. X. Levander, O. D. Dubon, L. A. Reichertz, N. Lopez, M. Nishio, and W. Walukiewicz, "Demonstration of ZnTe1-xOx intermediate band solar cell," Jpn. J. Appl. Phys., vol. 50, pp. 082304-1082304-3, 2011.

[32] A. Luque, P. G. Linares, E. Antolín, E. Cánovas, C. D. Farmer, C. R. Stanley, and A. Martí, "Multiple levels in intermediate band solar cells," Appl. Phys. Lett., vol. 96, pp. 013501-1-013501-3, 2010.

[33] R. Oshima, A. Takata, and Y. Okada, "Strain-compensated InAs/GaNAs quantum dots for use in high-efficiency solar cells," Appl. Phys. Lett., vol. 93, pp. 083111-1-083111-3, Aug. 2008.

[34] V. Popescu, G. Bester, M. C. Hanna, A. G. Norman, and A. Zunger, "Theoretical and experimental examination of the intermediate-band concept for strain-balanced (In, Ga) As/Ga (As, P) quantum dot solar cells," Phys. Rev. B, vol. 78, pp. 205321-1-205321-17, 2008.

[35] D. Alonso-Alvarez, B. Alén, J. M. Ripalda, A. G. Taboada, J. M. Llorens, Y. González, L. González, F. Briones, E. Antolín, I. Ramiro, A. Martí, A. Luque, M. A. Roldán, J. Hernandez-Saz, M. Herrera, and S. I. Molina, "Strain balanced quantum posts for intermediate band solar cells," in Proc. 35th IEEE Photovoltaic Spec. Conf., 2010, pp. 000928-000933.

[36] R. Laghumavarapu, M. El-Emawy, N. Nuntawong, A. Moscho, L. Lester, and D. Huffaker, "Improved device performance of InAs/GaAs quantum dot solar cells with GaP strain compensation layers," Appl. Phys. Lett., vol. 91, pp. 243115-1-243115-3, 2007

[37] W.-S. Liu, H.-M. Wu, F.-H. Tsao, T.-L. Hsu, and J.-I. Chyi, "Improving the characteristics of intermediate-band solar cell devices using a vertically aligned InAs/GaAsSb quantum dot structure," Sol. Energy Mater. Sol. Cells, vol. 105, pp. 237-241, 2012.

[38] S. A. Blokhin, A. V. Sakharov, A. M. Nadtochy, A. S. Pauysov, M. V. Maximov, N. N. Ledentsov, A. R. Kovsh, S. S. Mikhrin, V. M. Lantratov, and S. A. Mintairov, "AlGaAs/GaAs photovoltaic cells with an array of InGaAs QDs," Semiconductors, vol. 43, pp. 514-518, 2009.

[39] A. Luque, A. Martí, C. Stanley, N. López, L. Cuadra, D. Zhou, J. L. Pearson, and A. McKee, "General equivalent circuit for intermediate band devices: Potentils, currents and eleactroluminescence," J. Appl. Phys., vol. 96, pp. 903-909, 2004.

[40] K. A. Sablon, J. W. Little, V. Mitin, A. Sergeev, N. Vagidov, and K. Reinhardt, "Strong enhancement of solar cell efficiency due to quantum dots with built-in charge," Nano Lett., vol. 11, pp. 2311-2317, 2011.

[41] D. Zhou, G. Sharma, S. Thomassen, T. Reenaas, and B. Fimland, "Optimization towards high density quantum dots for intermediate band solar cells grown by molecular beam epitaxy," Appl. Phys. Lett., vol. 96, pp. 061913-1-061913-3, 2010.
[42] F. K. Tutu, I. R. Sellers, M. G. Peinado, C. E. Pastore, S. M. Willis, A. R. Watt, T. Wang, and H. Y. Liu, "Improved performance of multilayer InAs/GaAs quantum-dot solar cells using a high-growth-temperature GaAs spacer layer," J. Appl. Phys., vol. 111, pp. 046101-1-046101-3, 2012.

[43] R. Laghumavarapu, A. Moscho, A. Khoshakhlagh, M. El-Emawy, L. Lester, and D. Huffaker, "GaSb/GaAs type II quantum dot solar cells for enhanced infrared spectral response," Appl. Phys. Lett., vol. 90 , pp. 173125-1-173125-3, 2007.

[44] D. Alonso-Álvarez, B. Alén, J. M. García, and J. M. Ripalda, "Optical investigation of type II GaSb/GaAs self-assembled quantum dots," Appl. Phys. Lett., vol. 91, pp. 263103-1-263103-3, 2007.

[45] P. J. Carrington, A. S. Mahajumi, M. C. Wagener, J. R. Botha, Q. Zhuang, and A. Krier, "Type II GaSb/GaAs quantum dot/ring stacks with extended photoresponse for efficient solar cells," Physica B, Condensed Matter, vol. 407, pp. 1493-1496, 2012.

[46] I. Ramiro, E. Antolin, M. J. Steer, P. G. Linares, E. Hernandez, I. Artacho, E. Lopez, T. Ben, J. M. Ripalda, and S. I. Molina, "InAs/AlGaAs quantum dot intermediate band solar cells with enlarged sub-bandgaps," in Proc. 38th Photovoltaic Spec. Conf., 2012, pp. 000652-000656.

[47] C. Schneider, S. Kremling, N. Tarakina, T. Braun, M. Adams, M. Lermer S. Reitzenstein, L. Worschech, M. Kamp, and S. Höfling, "AlGaInAs quantum dot solar cells: tailoring quantum dots for intermediate band formation," Semicond. Sci. Technol., vol. 27, pp. 032002-1-032002-5, 2012.

[48] A. Scaccabarozzi, S. Adorno, S. Bietti, M. Acciarri, and S. Sanguinetti, "Evidence of two-photon absorption in strain-free quantum dot GaAs/AlGaAs solar cells," Physica Status Solidi (RRL)-Rapid Res. Lett., vol. 7, pp. 173-176, 2013.

[49] J. Wu, Z. M. Wang, V. G. Dorogan, S. Li, Z. Zhou, H. Li, J. Lee, E. S. Kim, Y. I. Mazur, and G. J. Salamo, "Strain-free ring-shaped nanostructures by droplet epitaxy for photovoltaic application," Appl. Phys. Lett., vol. 101, pp. 043904-1-043904-4, 2012.

[50] A. G. Norman, M. Hanna, P. Dippo, D. Levi, R. Reedy, J. Ward, and M. AlJassim, "InGaAs/GaAs QD superlattices: MOVPE growth, structural and optical characterization, and application in intermediate-band solar cells," in Proc. 31st IEEE Photovoltaic Spec., 2005, pp. 43-48.

[51] T. Sugaya, O. Numakami, R. Oshima, S. Furue, H. Komaki, T. Amano, K. Matsubara, Y. Okano, and S. Niki, "Ultra-high stacks of InGaAs/GaAs quantum dots for high efficiency solar cells," Energy Environ. Sci., vol. 5, pp. 6233-6237, 2012.

[52] Y. Okada, T. Morioka, K. Yoshida, R. Oshima, Y. Shoji, T. Inoue, and T. Kita, "Increase in photocurrent by optical transitions via intermediate quantum states in direct-doped InAs/GaNAs strain-compensated quantum dot solar cell," J. Appl. Phys., vol. 109, pp. 024301-1-024301-5, 2011.

[53] P. W. Fry, I. E. Itskevich, S. R. Parnell, J. J. Finley, L. R. Wilson, K. L. Schumacher, D. J. Mowbray, M. S. Skolnick, M. Al-Khafaji, and A. G. Cullis, "Photocurrent spectroscopy of InAs/GaAs self-assembled quantum dots," Phys. Rev. B, vol. 62, pp. 16784-16791, 2000.

[54] W. H. Chang, T. M. Hsu, C. C. Huang, S. L. Hsu, C. Y. Lai, N. T. Yeh, T. E. Nee, and J. I. Chyi, "Photocurrent studies of the carrier escape process from InAs self-assembled quantum dots," Phys. Rev. B, vol. 62, pp. 6959-6962,2000.

[55] S. J. Xu, S. J. Chua, T. Mei, X. C. Wang, X. H. Zhang, G. Karunasiri, W. J. Fan, C. H. Wang, J. Jiang, and S. Wang, "Characteristics of InGaAs quantum dot infrared photodetectors," Appl. Phys. Lett., vol. 73, p. 3153, 1998.

[56] Z. Chen, O. Baklenov, E. Kim, I. Mukhametzhanov, J. Tie, A. Madhukar, Z. Ye, and J. Campbell, "Normal incidence InAs/AlGaAs quantum dot infrared photodetectors with undoped active region," J. Appl. Phys., vol. 89 , pp. 4558-4563, 2001.

[57] L. Jiang, S. S. Li, N.-T. Yeh, and J.-I. Chyi, "An In0. 6Ga0. 4As/GaAs quantum dot infrared photodetector with operating temperature up to 260 K," in Proc. AeroSense, 2003, pp. 677-684.

[58] A. Martí, N. Lopez, E. Antolín, E. Canovas, A. Luque, C. R. Stanley, C. D. Farmer, and P. Díaz, "Emitter degradation in quantum dot intermediate band solar cells," Appl. Phys. Lett., vol. 90, pp. 233510-1-233510-3, 2007.

[59] M. A. Green, K. Emery, Y. Hishikawa, W. Warta, and E. D. Dunlop, "Solar cell efficiency tables (ver. 39)," Progress Photovoltaics, Res. Appl, vol. 20, pp. $12-20,2011$

[60] E. Antolín, A. Martí, P. G. Linares, I. Ramiro, E. Hernández, C. D. Farmer, C. R. Stanley, and A. Luque, "Advances in Quantum dot intermediate band solar cells," in Proc. 35th Photovoltaic Spec. Conf., 2010, pp. 0006500070 . 
[61] A. Luque, A. Marti, N. Lopez, E. Antolin, E. Canovas, C. Stanley, C. Farmer, L. J. Caballero, L. Cuadra, and J. L. Balenzategui, "Experimental analysis of the quasi-Fermi level split in quantum dot intermediate-band solar cells," Appl. Phys. Lett., vol. 87, pp. 083505-1-083505-3, 2005.

[62] A. A. Abouelsaood, M. Y. Ghannam, and J. Poortmans, "On the reported experimental evidence for the quasi-Fermi level split in quantum-dot intermediate-band solar cells," Progress Photovoltaics, Res. Appl., 2011.

[63] S. Sauvage, P. Boucaud, F. Julien, J.-M. Gérard, and V. Thierry-Mieg, "Intraband absorption in n-doped InAs/GaAs quantum dots," Appl. Phys. Lett., vol. 71, pp. 2785-2787, 1997.

[64] J. Phillips, K. Kamath, X. Zhou, N. Chervela, and P. Bhattacharya, "Photoluminescence and far-infrared absorption in Si-doped self-organized InAs quantum dots," Appl. Phys. Lett., vol. 71, pp. 2079-2081, 1997.

[65] C. Dürr, R. Warburton, K. Karrai, J. Kotthaus, G. Medeiros-Ribeiro, and P. Petroff, "Interband absorption on self-assembled InAs quantum dots," Physica E: Low-dimensional Syst. Nanostruct., vol. 2, pp. 23-27, 1998.

[66] J. Wu, D. Shao, Z. Li, M. O. Manasreh, V. P. Kunets, Z. M. Wang, and G. J. Salamo, "Intermediate-band material based on GaAs quantum rings for solar cells," Appl. Phys. Lett., vol. 95, pp. 071908-1-071908-3, 2009.

[67] R. Leon, S. Fafard, D. Leonard, J. Merz, and P. Petroff, "Visible luminescence from semiconductor quantum dots in large ensembles," Appl. Phys. Lett., vol. 67, pp. 521-523, 1995.

[68] B. Sun, Z. Lu, D. Jiang, J. Wu, Z. Xu, Y. Wang, J. Wang, and W. Ge, "Photovoltage and photoreflectance spectroscopy of InAs/GaAs self-organized quantum dots," Appl. Phys. Lett., vol. 73, pp. 2657-2659, 1998.

[69] D. Sizov, Y. B. Samsonenko, G. Tsyrlin, N. Polyakov, V. Egorov, A. Tonkikh, A. Zhukov, S. Mikhrin, A. Vasil'ev, and Y. G. Musikhin, "Structural and optical properties of InAs quantum dots in AlGaAs matrix," Semiconductors, vol. 37, pp. 559-563, 2003.

[70] K. Brunner, U. Bockelmann, G. Abstreiter, M. Walther, G. Böhm, G. Tränkle, and G. Weimann, "Photoluminescence from a single GaAs/AlGaAs quantum dot," Phys. Rev. Lett., vol. 69, pp. 3216-3219, 1992.

[71] J. Tatebayashi, A. Khoshakhlagh, S. Huang, L. Dawson, G. Balakrishnan, and D. Huffaker, "Formation and optical characteristics of strain-relieved and densely stacked GaSb/GaAs quantum dots," Appl. Phys. Lett., vol. 89, pp. 203116-1-203116-3, 2006.

[72] M. Geller, C. Kapteyn, L. Muller-Kirsch, R. Heitz, and D. Bimberg, "450 $\mathrm{meV}$ hole localization in GaSb/GaAs quantum dots," Appl. Phys. Lett., vol. 82, pp. 2706-2708, 2003.

[73] S. Fafard, Z. R. Wasilewski, C. N. Allen, D. Picard, M. Spanner, J. P. McCaffrey, and P. G. Piva, "Manipulating the energy levels of semiconductor quantum dots," Phys. Rev. B, vol. 59, pp. 15368-15373, 1999

[74] E. Cánovas, A. Martí, N. López, E. Antolín, P. Linares, C. Farmer, C. Stanley, and A. Luque, "Application of the photoreflectance technique to the characterization of quantum dot intermediate band materials for solar cells," Thin Solid Films, vol. 516, pp. 6943-6947, 2008.

[75] D. F. Marrón, E. Cánovas, I. Artacho, C. Stanley, M. Steer, T. Kaizu, Y. Shoji, N. Ahsan, Y. Okada, and E. Barrigón, "Application of photoreflectance to advanced multilayer structures for photovoltaics," Mater. Sci. Eng., B, 2012.

[76] N. Ahsan, N. Miyashita, M. Monirul Islam, K. Man Yu, W. Walukiewicz, and Y. Okada, "Two-photon excitation in an intermediate band solar cell structure," Appl. Phys. Lett., vol. 100, pp. 172111-1-172111-4, 2012.

[77] N. Ahsan, N. Miyashita, M. M. Islam, K. M. Yu, W. Walukiewicz, and Y. Okada, "Effect of Sb on GaNAs intermediate band solar cells," IEEE J. Photovoltaics, vol. 3, no. 2, pp. 730-736, Apr. 2013.

[78] T. Tanaka, M. Miyabara, Y. Nagao, K. Saito, Q. Guo, M. Nishio, K. M. Yu, and W. Walukiewicz, "Photocurrent induced by two-photon excitation in ZnTeO intermediate band solar cells," Appl. Phys. Lett., vol. 102, pp. 052111-1-052111-4, 2013.

[79] W. Wang, A. S. Lin, and J. D. Phillips, "Intermediate-band photovoltaic solar cell based on ZnTe: O," Appl. Phys. Lett., vol. 95, pp. 011103-1011103-3, 2009.

[80] E. Antolín, I. Ramiro, E. López, E. Hernández, I. Artacho, C. Tablero, A. Martí, A. Luque, J. Chen, J. Foley, and J. D. Phillips, "Intermediate band to conduction band optical absorption in $\mathrm{ZnTeO}$," in Proc. 38th Photovoltaic Spec. Conf., 2012, pp. 1-5.

[81] Y. Kuang, K. Yu, R. Kudrawiec, A. Luce, M. Ting, W. Walukiewicz, and C. Tu, "GaNAsP: An intermediate band semiconductor grown by gassource molecular beam epitaxy," Appl. Phys. Lett., vol. 102, pp. 112105 $1-112105-4,2013$.

[82] K. Yu, W. Walukiewicz, J. Ager, D. Bour, R. Farshchi, O. Dubon, S. Li, I. Sharp, and E. Haller, "Multiband GaNAsP quaternary alloys," Appl. Phys. Lett., vol. 88, pp. 092110-1-092110-3, 2006.
[83] P. G. Linares, A. Martí, E. Antolín, I. Ramiro, E. López, E. Hernández, D. Fuertes Marrón, I. Artacho, I. Tobías, P. Gérard, C. Chaix, R. P. Campion, C. T. Foxon, C. R. Stanley, S. I. Molina, and A. Luque, "Extreme voltage recovery in GaAs: Ti intermediate band solar cells," Sol. Energy Mater. Sol. Cells, vol. 108, pp. 175-179, 2013.

[84] J.-K. Sheu, F.-W. Huang, Y.-H. Liu, P. Chen, Y.-H. Yeh, M.-L. Lee, and W.-C. Lai, "Photoresponses of manganese-doped gallium nitride grown by metalorganic vapor-phase epitaxy," Appl. Phys. Lett., vol. 102, pp. 0711071-071107-3, 2013.

[85] B. Marsen, L. Steinkopf, A. Singh, H. Wilhelm, I. Lauermann, T. Unold, R. Scheer, and H. W. Schock, "Effects of Ti-incorporation in CuInS2 solar cells," Sol. Energy Mater. Sol. Cells, vol. 94, pp. 1730-1733, 2010.

[86] S. Sonoda, "Partially filled intermediate band of Cr-doped GaN films," Appl. Phys. Lett., vol. 100, pp. 202101-1-202101-4, 2012.

Íñigo Ramiro received the Engineering degree in telecommunication from the Universidad Politécnica de Madrid (UPM), Madrid, Spain, and from the Institut National des Télécommunications, Evry, France, in 2007. He is currently working toward the Ph.D. degree with the Instituto de Energía Solar, Escuela Técnica Superior de Ingenieros de Telecomunicación, UPM, Madrid, in the development and characterization of intermediate band solar cells from which he has a UPM Doctoral Grant.

Antonio Martí (M'12) received the Licenciado en Físicas M.S. degree from the Universidad Complutense de Madrid, Madrid, Spain, in 1987 and the Ph.D. degree (summa cum laude) from the Universidad Politécnica de Madrid (UPM), Madrid, in 1992.

Since 1987, he has been with the Instituto de Energía Solar, Escuela Técnica Superior de Ingenieros de Telecomunicación, UPM, first as a Research Assistant in 1988, as a Professor in 1992, and as a Chair Professor in 2006. He has published more than 120 international papers and conference contributions in the field of photovoltaics.

Dr. Martí received the Best Doctoral Thesis award in 1992 and the Junior Research Award in 2000, both from the UPM.

Elisa Antolín received the Licenciado en Físicas M.S. degree in 2001 from the Universidad Autónoma de Madrid, Madrid, Spain, and the Ph.D. degree (cum laude) from the Universidad Politécnica de Madrid (UPM), Madrid, in 2010.

In 2011, she received a Juan de la Cierva Postdoctoral Grant and worked with the Instituto de Microelectrónica de Madrid-Consejo Superior de Investigaciones Científicas, Madrid. She is currently a Marie Curie Postdoctoral Fellow with the School of Physics and Astronomy, University of Nottingham, Nottingham, U.K., and she still collaborates with the Instituto de Energía Solar, as she has been since 2004 .

Dr. Antolín received the Best Doctoral Thesis award from the UPM in 2011.

Antonio Luque (S'62-M'77-SM' 77) received the Dr. Eng. degree in telecommunication from the Universidad Politécnica de Madrid, Madrid, Spain, in 1969.

$\mathrm{He}$ is currently an Emeritus Chair Professor of electronic technology with the Universidad Politécnica de Madrid. Since 1970, he has led the Instituto de Energía Solar, Escuela Técnica Superior de Ingenieros de Telecomunicación, Universidad Politécnica de Madrid, which he founded in 1979. He invented the bifacial cell in 1976, and more recently, he has proposed the intermediate band solar cell. He has published more than 250 scientific papers in the English language, as well as several books and patents. His research interests include the photovoltaic conversion of solar energy.

Dr. Luque received the Spanish National Prize for Technology, the AlexanderEdmond Becquerel Prize in photovoltaic research, the King James I Award for environmental research, the Juan de la Cierva Award, the William Cherry Award, and the Solar World Einstein Award. 